\title{
Ultrasound Alongside with Mammogram in Women with Physically Dense Breast
}

\author{
Fadak S. Alshayookh, Howayda M. Ahmed, Ibrahim A. Awad, Saddig D. Jastaniah* \\ Department of Diagnostic Radiology, Faculty of Applied Medical Sciences, King Abdulaziz University, Jeddah, \\ KSA \\ Email: ${ }^{*}$ sjastaniah@kau.edu.sa
}

Received 19 April 2014; revised 16 May 2014; accepted 12 June 2014

Copyright (C) 2014 by authors and Scientific Research Publishing Inc.

This work is licensed under the Creative Commons Attribution International License (CC BY).

http://creativecommons.org/licenses/by/4.0/

c) (i) Open Access

\section{Abstract}

We report usefulness of ultrasound used as an adjunct diagnostic tool to mammogram in routine annual checkup for women breasts of certain ages and breast mass. The purpose of breast imaging is to detect areas of tissue distortion and breast cancers. A mammogram is the common diagnostic imaging modality used to find breast diseases but sometimes the mammogram might not give the doctor enough information especially in women with dense breasts. As a result, the patient may be asked to undergo ultrasound or magnetic resonance imaging as a better mean of judgment to the case. Because ultrasound is widely used, simple and safe to patients we were encouraged to emphasis on exploring its role adjunct to mammogram. A retrospective observation study was done at the diagnostic radiology department at King Abdulaziz University Hospital (KAUH) in the period from January 2012 to June 2012; we covered all women with dense breasts in mammography and ultrasound units. The study group was 40 patients. All patients were imaged with both mammography and ultrasound. The statistical measures of accuracy, sensitivity and specificity were calculated using the SPSS program. The results we obtained suggest that age and the physical density of breast potentially affect mammogram images of women with 41 years or smaller with sensitivity $66 \%$ and specificity $68 \%$. Therefore, we recommend using ultrasound alongside the mammogram in women with dense breast for better diagnosis of small cancers that were not identified on mammography or clinical breast examination alone.

\section{Keywords}

Ultrasound, Mammogram, Dense Breasts, Women Breasts

\section{Introduction}

Regular, systematic imaging of breast tissue is fundamental to the detection of altered breast architecture, al*Corresponding author.

How to cite this paper: Alshayookh, F.S., Ahmed, H.M., Awad, I.A. and Jastaniah, S.D. (2014) Ultrasound Alongside with Mammogram in Women with Physically Dense Breast. Advances in Breast Cancer Research, 3, 88-95. 
lowing for sampling, analysis and identification of benign or malignant potential. Breast imaging can be achieved with magnetic resonance imaging, mammography and ultrasound alone or in combination, although, performance of obtaining information from mammography is reduced due to overlying of tissues in dense breast [1].

Breast density refers to the relative amount of fibrous and glandular tissue which attenuates $\mathrm{x}$-rays on a mammogram. The breast density impacts breast cancer detection. While there are limitations of breast density measures, multiple studies demonstrate that breast cancer risk is increased for women with dense breasts. The decreased sensitivity of mammography in dense breasts is a major limitation of mammography [2].

Dense breasts do not indicate abnormality, but may increase risk of breast cancer. However, experts do not agree which modality should be used in such cases in addition to mammograms [3].

It has been reported [4] that the density of dense structures such as the milk ducts is similar to the tumor making it difficult to interpret. Increased breast density is known to cause a parallel decrease in mammographic sensitivity suggesting there is a need for additional imaging if adequate interrogation of breast tissue is to occur [5].

Recent research documents that increased breast density can be acknowledged as an independent risk factor for breast cancer, with imaging of both mammography and bilateral whole breast ultrasound now considered to be the best practice. Patients with dense breast tissue may additionally have other risk factors and even though a mammographic examination may have a negative result, it is appropriate to provide additional imaging [6].

Mammographic images are assessing for the presence of mass/es, asymmetric focal density, architectural distortion and the presence of micro-calcifications. The clinical findings should be document including comment on palpable lumps, tissue thickening, and skin puckering or nipple retractions. The size, shape, density and margins of all masses are noted. The distribution and morphology of micro-calcifications, multi-focal and multi-centric lesions, architectural distortion of the breast tissue and skin thickening are all reported [7].

Ultrasound is widely used, simple and safe to patients [8]. It images tissues of the breast to the chest wall via a technique known as cross-sectional technique in order to display the tissue with no overlap [5] [9].

Breast ultrasound as is it known today, had its roots in military technology, with initial developments occurring more than 50 years ago. In the past it was noted that ultrasound was "not seen as a breast screening tool" but was commonly used to evaluate breast abnormalities found at mammography [10]. In the current clinical setting, breast ultrasound is often seen as an integral part of breast imaging programs. The ultrasound has revolutionized the evaluation of breast abnormalities with providing a rapid, cost effective, and accurate guidance method for a wide range of interventional techniques [11]. Targeted breast ultrasound is used to interrogate a specific area of breast tissue, and is widely accepted as a diagnostic tool for the evaluation of palpable and non-palpable breast abnormalities in conjunction with mammography [12].

The ultrasound is not a screening tool and cannot replace mammography. This study aims at demonstrating the importance of using ultrasound as together with mammography to each annual screen for women with dense breasts.

\section{Materials and Methods}

\subsection{Patients and Methods}

Our observation study was done at the diagnostic radiology department at KAUH after obtaining research ethical approval. The study was done during the academic year 2012. Within about the first six months of 2012; we covered all women with dense breasts in mammography and ultrasound department. After exclusion unwanted cases, the group study was 40 patients. Patients imaged both using mammography and ultrasound (Figure 1 and Figure 2). The statistical measures of accuracy, sensitivity and specificity were calculated using the SPSS program.

\subsection{Patients}

The study was a retrospective, nonrandomized, observational clinical case series. We retrospectively analyzed the records of patients diagnosed they have problem related with dense breast and registered in the clinic between January 2012 and Jun 2012. The total number of patients who presented for breast imaging during this time was 356 patients. The exclusion criteria were patients who either had previous breast diseases (113 pa- 


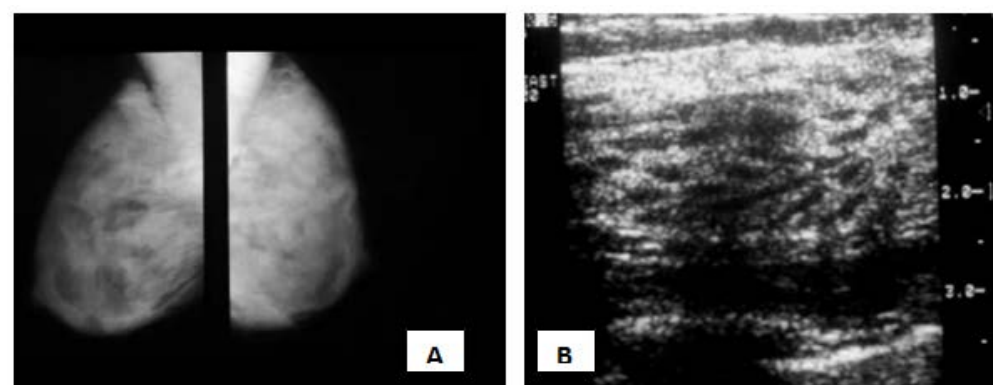

Figure 1. Normal mammographic (A) and ultrasound (B) images of dense breast.
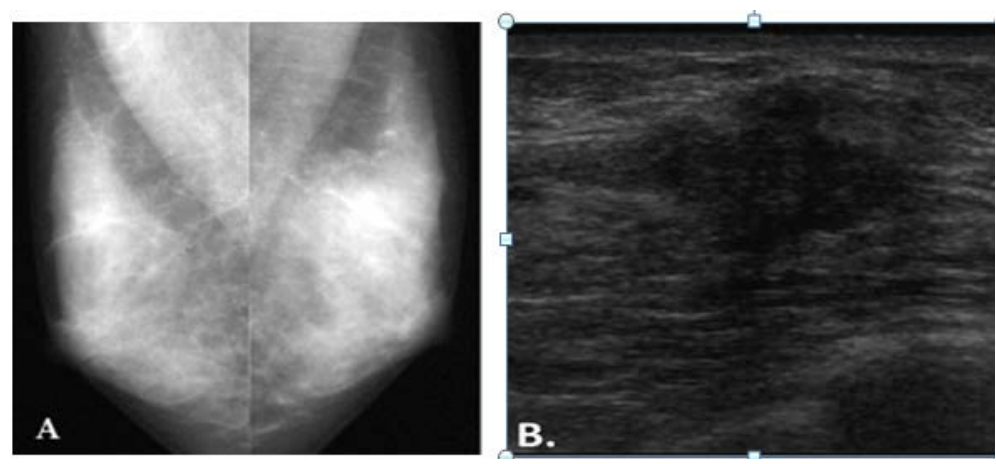

Figure 2. Palpable left dense breast lump. (A) Whole-breast mediolateral mammographic image reveals no abnormality; (B) Ultrasound image shows solid mass with irregular shape, indistinct and angular margins. Histopathology revealed invasive ductal carcinoma.

tients), or who has fatty breast parenchyma —not a dense breast—(93 patients), or only mammography examination was done (75 patients), or only ultrasound examination was done (35 patients). So, our sample is 40 patients with dense breast parenchyma. The patients' ages range from 34 to 61 years. All the patients within the study group had both mammogram and ultrasound examinations in the standard technique which is mentioned in the previous chapter. The images then sent to PACS.

\subsection{Image Interpretation}

The images produced were autonomously evaluated using PACS workstations with the help of qualified radiologist with good experience in breast mammogram and ultrasound .The images of each patient were reviewed with computer aided analysis in the plans which are performed. The radiologist also makes comments on the presence of anatomical variations of breast including flat nipple, inverted nipple, large breast and large nipple, etc.

\subsection{Statistical Analysis}

Demographic data of participants together with mammogram and ultrasound findings were collected and statistically analyzed using the SPSS program to find and show the relationship between both findings and which is stronger modality in case of dense breast by the sensitivity and specificity test.

\section{Results}

The total of 40 patients was collecting from KAU hospital within about the first six months of 2012, their age ranged from 34 to 61. According to the World Health Organization for the division of ages (WHO), the category of young adult patient will be aged from 20 to 40 years old and the category of middle adult patient will be aged from 40 to 65 years old. The mean in this sample is 45.5 years and standard deviation is 6.82 years indicate to 
variation and skewness is 0.355 indicate to most of age distribution less than mean. This means the average of age is 45.5 years which is located within interval $+6.820,-6.820$ and most of age less than 35 years. As we see (Table 1) represented basic statistics of age as mean, standard deviation and skewness. Figure 3 also shows distribution of age by category: Young adult (20 - 40) and Middle adult (40 - 65). In Figure 4 below we can see the method of diagnosis which is used. The Mammogram was detect perfectly as Ultrasound (same result) in 37.5\%, 4 of patient was in young adult category and 11 was in middle adult category. While the Ultrasound was superiority in diagnosis and detects $62.5 \%$ of cases, 7 patients was in young adult category and 18 were in middle adult category. Cross tabulation shows the methods used in each age category (Table 2) and graph it that in (Figure 5).

When the sensitivity and Specificity test was done, the area under the curve was 0.511 with standard error for them was 0.096 and 95\% confidant interval from 0.322 to 0.699 as shown in (Table 3). But we can see the area under the curve was not a significant which means that may diagnosed by Mammogram and Ultrasound doesn't have any sense different if patient age equal or greater than 41.5 years old. In the patient age less than 41.5 years old, the sensitivity of mammogram is decreased and the differences between mammogram and ultrasound results will appear.

As a result, the best cut-off that maximize (sensitivity + specificity) was 41.5 years old. At this duration, the sensitivity was 0.667 and specificity was $0.680(1-$ Specificity $=0.320)$. The ROC Curve obtained by different cut-offs shows Curve of Sensitivity \& Specificity (Figure 6).

For diagnostic method, the odds ratio was 1.069. So, we can say the odds of diagnosed by Ultrasound among age ranged are 1.069 times the odds of diagnosed by Mammogram among age ranged (Table 4). The risk ratio of US was 1.025. That means the ultrasound diagnosed 1.025 times as more useful to Mammogram diagnosed specially for young adult age. While the limits for odds ratio and risk ratio of mammogram and ultrasound. Risk ratio of both mammogram for middle adult age and ultrasound was 0.959 times as less useful to ultrasound diagnosed alone specially (Table 4) shows all the previous with lower and upper.

Table 1. The basic statistics of age as mean, standard deviation and skewness.

\begin{tabular}{cccc}
\hline & Descriptive Statistic \\
\hline Variables & Mean & Standard Deviation & Skewness \\
Age & 45.50 & 6.820 & 0.355 \\
\hline
\end{tabular}

Table 2. Cross tabulation.

\begin{tabular}{crcc}
\hline \multicolumn{2}{l}{ Variables } & \multicolumn{2}{c}{ Diagnosis Method } \\
\cline { 3 - 4 } Age & Young Adult & Ultrasound & Mammo. \& US \\
& Middle Adult & 7 & 4 \\
& & 18 & 11 \\
\hline
\end{tabular}

Table 3. ROC Curve variables.

\begin{tabular}{cccccc}
\hline & \multicolumn{5}{c}{ Receiver Operator Characteristic (ROC) Curve } \\
\hline \multirow{2}{*}{$\begin{array}{c}\text { Variables } \\
\text { Age }\end{array}$} & Area & Std. Error & P-Value & Lower & Upper \\
& 0.511 & 0.096 & 0.911 & 0.322 & 0.699 \\
\hline
\end{tabular}

Table 4. The odds and risk ratio.

\begin{tabular}{|c|c|c|c|}
\hline \multicolumn{4}{|c|}{ Risk \& Odds } \\
\hline \multirow{2}{*}{ Ratio } & \multirow{2}{*}{ Estimate } & \multicolumn{2}{|c|}{$95 \%$ CI } \\
\hline & & Lower & Upper \\
\hline Odds & 1.069 & 0.254 & 4.511 \\
\hline Risk for US & 1.025 & 0.604 & 1.741 \\
\hline Risk for US \& MG & 0.959 & 0.386 & 2.381 \\
\hline
\end{tabular}




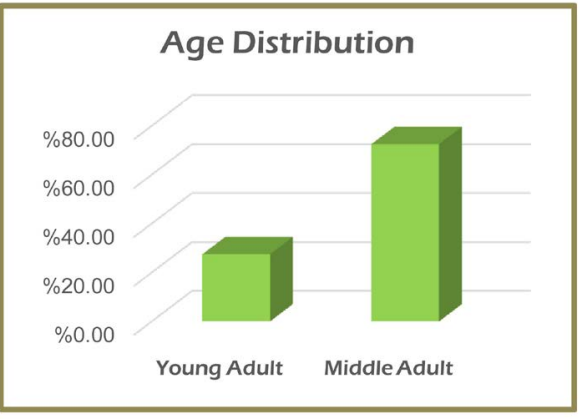

Figure 3. The distribution of age by category: Young adult (20 40 Y) \& Middle adult (40 - 65 Y).

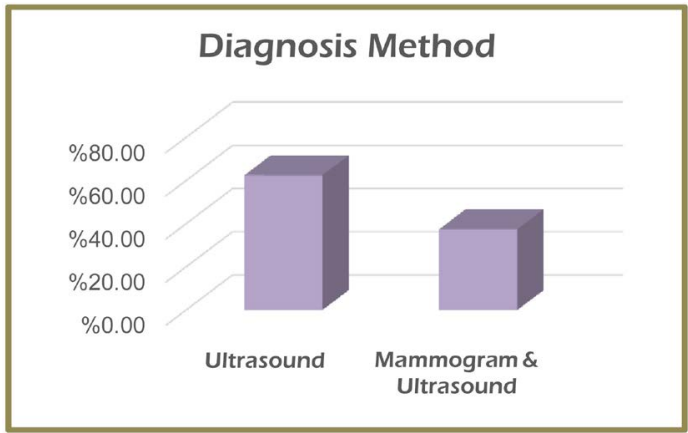

Figure 4. The method of diagnosis (Ultrasound \& Mammogram).

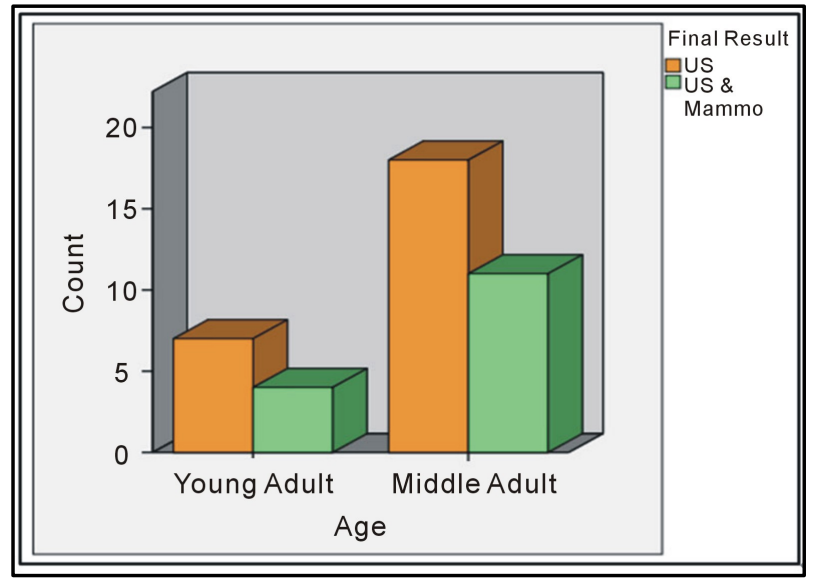

Figure 5. Theimaging modality and age category.

\section{Discussion}

Mammographic sensitivity is proven to be significantly compromised when imaging dense breast tissue and research now documents dense tissue as an independent risk factor. Imaging with both mammography and ultrasound is now suggested by several authors as best practice for these patients, with mammography no longer viewed as the gold standard of imaging. Many authors comment on the comparative sensitivity of mammography and ultrasound and several studies have attempted to quantify the differences in sensitivity and detection rates relative to patient ages and breast density. Several authors agree that the use of ultrasound and mammography may have a combined sensitivity as high as $96 \%-100 \%$.

Lumps, both benign and cancerous, appear white on a mammogram; similarly, dense tissue also appears white. 


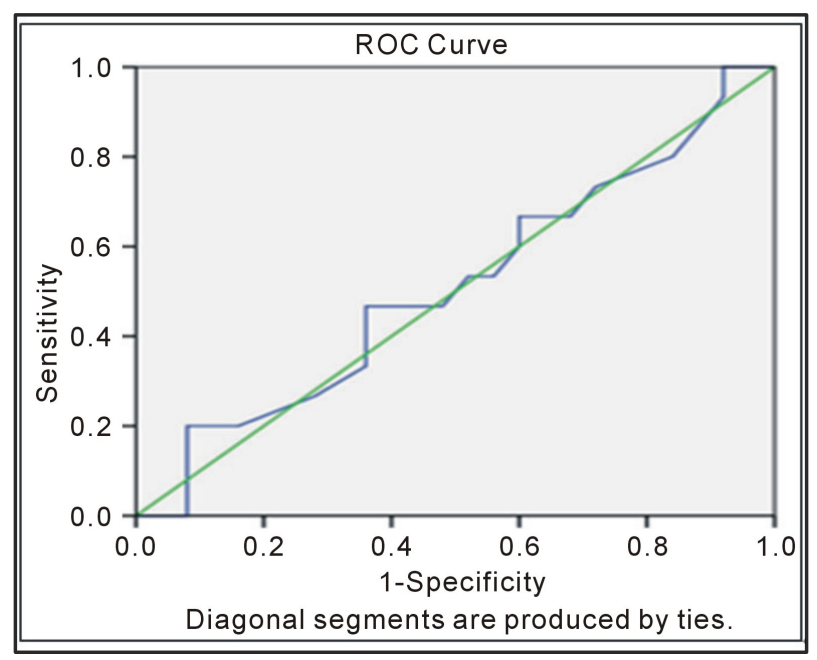

Figure 6. Diagnosed curve of sensitivity \& specificity.

Therefore, mammograms is not helpful in women with dense breasts [2] [13].

Breast density is not fixed but may change over time. Paradoxically, breast density tends to gradually decreases with age although overall risk increases with age showing survival benefit of screening women with dense breasts with supplemental whole breast ultrasound screening (WB-US) in addition to mammography. Screening WB-US has been investigated in high-risk women and in women with dense breasts. WB-US in addition to screening mammography has increased cancer detection compared to mammography alone. At prevalent screening, the cancer detection rate increased from 7.6/1000 by mammography alone to 11.8/1000 with mammography and WB-US [14].

Other research has shown that dense breast tissue provides additional risk factor for breast cancer, and the level of that risk has been quantified at 4 - 6 times the normal risk or radiographic density reduces the sensitivity of mammography in women whose tissue density is to $<60 \%$ [15] [16]. Overall, given a normally distributed mammography screening population, mammography is considered to be $80 \%-90 \%$ effective in detecting cancers in women without symptom [17].

The dense glandular tissue appears white on the mammogram, while fatty breast tissue appears black. Unfortunately, cancers also typically appear white, allowing the dense tissue to mask cancers and other lesions. This is particularly true of small cancers that may be hidden "behind" even a small area of density [18].

On the other hand, ultrasound should not be used alone for screening women with dense breast tissue because there are certain tissue characteristics, like micro calcifications, that are imaged very well by mammography, but poorly or not at all by ultrasound. Micro-calcifications are commonly associated with DCIS, and also with one particularly aggressive form of breast cancer. Ultrasound does not image calcifications as well as mammography [19]. Ultrasound and mammogram together found $82 \%$ of the breast cancers. Mammogram alone found only 53\% of the cancers [20] [21].

We believe that ultrasound is of great value as a first line of imaging in the assessment of young or pregnant symptomatic women, followed by mammography if deemed necessary this is in agreement with previous studies [22]. The ultrasound has a greater ability than mammography to demonstrate lesion characteristics as the transducer can be maneuvered through multiple planes [7]. The main goal of ultrasound has been preventing unnecessary biopsies of benign lesions and finding carcinomas that are missed by clinical and/or mammographic evaluation. Ultrasound is seen as attractive for supplemental screening as it is widely available, well tolerated by patients, and relatively inexpensive, involving no radiation [12]. With the development of improved technology and higher-frequency transducers, ultrasound has been indicated as a tool to help differentiate benign from malignant solid breast masses [23]. High resolution real-time ultrasound allows detailed visualization of many abnormal breast masses, with further stating in a 2002 study that ultrasound was vital in the diagnosis of breast cysts and has "shown promise in the differentiation of benign from malignant solid masses [22].

When combined using mammography and ultrasound, [24] stated that the sensitivity is higher than from using mammogram alone. Ultrasound deems superior to mammography for the "vast proportion of patients and wor- 
thy of consideration as a first-line diagnostic and screening tool, to stand alongside mammography in equal partnership". And further, ultrasound is reported to be significantly better than mammography in case of detection of invasive breast cancer and the combination of the two modalities is an improvement, [25] agree with the previous authors stating that "ultrasound has greater sensitivity than mammography in the detection of soft tissue abnormalities within the breast. Ultrasound is positive in $93 \%$ of cases and mammography $87 \%$, whereas the combination of modalities proved positive in $96 \%$ of cases.

The sensitivity of mammography as $83.7 \%$ and ultrasound as $89.1 \%$, with the combined sensitivity of mammography and ultrasound, $94.6 \%$. Specificity is improved when mammography and ultrasound are combined (92\%) [26]. In a later study [27] assess the appropriate age below which ultrasound would be the more accurate breast imaging test. The choice of imaging is based partly on age, though it was not based on clear evidence for specific imaging choices. Generally, the expertise suggest that women smaller than 35 years in age should be imaged by ultrasound, while women bigger than 35 years should be imaged primary with mammography.

Results of this study show that combining both mammography and ultrasound has a greater sensitivity (96\%) than either sonography (81.7\%) or mammography alone (75.8\%). Reviews by [28] assess the role of ultrasound as an adjunct to mammography in the detection of breast cancer. Breast ultrasound can lower the number of indeterminate findings of mammography, by defining them as benign or malignant. An additional $0.35 \%$ breast cancer detection rate when ultrasound is used in conjunction with mammography for screening women with non-fatty breasts heterogeneously dense or extremely dense breast parenchyma [29].

\section{Conclusion}

The physical density of breast and the patient age potentially affect the accuracy of mammography. Our results showed that age and the physical density of breast potentially affect mammogram images of women with 41 years or younger with sensitivity $66 \%$ and specificity $68 \%$. Sensitivity improved with mammography in women older than 41 years. As a result, the diagnosis by using ultrasound alongside the mammogram are preferable imaging combination in such cases of women and considered that mammography and ultrasound the new gold standard in breast screening.

\section{References}

[1] Birdwell, R.L., Ikeda, D.M., O’Shaughnessy, K.F. and Sickles, E.A. (2001) Mammographic Characteristics of 115 Missed Cancers Later Detected with Screening Mammography and the Potential Utility of Computer-Aided Detection. Radiology, 219, 192-202. http://dx.doi.org/10.1148/radiology.219.1.r01ap16192

[2] Pinsky, R.W. and Helvie, M.A. (2010) Mammographic Breast Density: Effect on Imaging and Breast Cancer Risk. Journal of the National Comprehensive Cancer Network, 8, 1157-1164.

[3] Wirth, W., Nikitenko, D. and Lyon, J. (2005) Segmentation of Breast Region in Mammograms Using a Rule-Based Fuzzy Reasoning Algorithm. ICGST Graphics, Vision and Image Processing Journal, 5, 45-54.

[4] Asselin-Labat, M.L., Vaillant, F., Sheridan, J.M., Pal, B., Wu, D., Simpson, E.R., Yasuda, H., Smyth, G.K., Martin, T.J., Lindeman, G.J. and Visvader, J.E. (2010) Control of Mammary Stem Cell Function by Steroid Hormone Signalling. Nature, 465, 798-802. http://dx.doi.org/10.1038/nature09027

[5] Baker, S., Wall, M. and Bloomfield, A. (2005) Breast Cancer Screening for Women Aged 40-49 Years—What Does the Evidence Mean for New Zealand? The New Zealand Medical Journal, 118, 1-8.

[6] Carney, P.A., Miglioretti, D.L., Yankaskas, B.C., Kerlikowske, K., Rosenberg, R., Rutter, C.M., Geller, B.M., Abraham, L.A., Dignan, M., Cutter, G. and Ballard-Barbash, R. (2003) Individual and Combined Effects of Age, Breast Density, and Hormone Replacement Therapy Use on the Accuracy of Screening Mammography. Annals of Intern Medicine, 138, 168-175. http://dx.doi.org/10.7326/0003-4819-138-3-200302040-00008

[7] Dummin, L.J., Cox, M. and Plant, L. (2007) Prediction of Breast Tumor Size by Mammography and Sonography-A Breast Screen Experience. The Breast Journal, 16, 38-46. http://dx.doi.org/10.1016/j.breast.2006.04.003

[8] David, N., Jackie, S., Butler, L. and Lewis, R. (2006) Hole’s Human Anatomy and Physiology. 11th Edition, McGraw Hill Higher Education, 880-881.

[9] Liberman, L., Feng, T.L., Dershaw, D.D., Morris, E.A. and Abramson, A.F. (1998) US-Guided Core Breast Biopsy: Use and Cost-Effectiveness. Radiology, 208, 717-723.

[10] Warner, E., Plewes, D.B., Hill, K.A., Causer, P.A., Zubovits, J.T., Jong, R.A., Cutara, M.R., DeBoer, G., Yaffe, M.J, Messner, S.J., Meschino, W.S., Piron, C.A. and Narod, S.A. (2004) Surveillance of BRCA1 and BRCA2 Mutation 
Carriers with Magnetic Resonance Imaging, Ultrasound, Mammography, and Clinical Breast Examination. Journal of the American Medical Association, 292, 1317-1325. http://dx.doi.org/10.1001/jama.292.11.1317

[11] Dempsey, P.J. (2004) The History of Breast Ultrasound. Journal of Ultrasound in Medicine, 23, 887-894.

[12] Berg, W.A., Gutierrez, L., NessAiver, M.S., Carter, B., Bhargavan, M., Lewis, R.S. and Ioffe, O.B. (2004) Diagnostic Accuracy of Mammography, Clinical Examination, US, and MR Imaging in Preoperative Assessment of Breast Cancer. Radiology, 233, 830-849. http://dx.doi.org/10.1148/radiol.2333031484

[13] Kopans, D.B. (2008) Basic Physics and Doubts about Relationship between Mammographically Determined Tissue Density and Breast Cancer Risk. Radiology, 246, 348-353

[14] American College of Radiology (2003) Breast Imaging Reporting and Data System (BI-RADS). 4th Edition, American College of Radiology, Reston.

[15] Vacek, P.M. and Geller, B.M. (2004) A Prospective Study of Breast Cancer Risk Using Routine Mammographic Breast Density Measurements. Cancer Epidemiology, Biomarkers Prevention, 13, 715-722.

[16] Barlow, W.E., White, E., Ballard-Barbash, R., Vacek, P.M., Titus-Ernstoff, L., Carney, P.A., Tice, J.A., Buist, D.S.M., Geller, B.M., Rosenberg, R., Yankaskas, B.C. and Kerlikowske, K. (2006) Prospective Breast Cancer Risk Prediction Model for Women Undergoing Screening Mammography. Journal of the National Cancer Institute, 98, 1204-1214. http://dx.doi.org/10.1093/jnci/djj331

[17] American Cancer Society (2009-2010) Breast Cancer Facts \& Figures. American Cancer Society, Inc., Atlanta.

[18] Pisano, E.D., Hendrick, R.E., Yaffe, M.J., Baum, J.K., Acharyya, S., Cormack, J.B., et al. (2008) Diagnostic Accuracy of Digital Mammography versus Film Mammography: Exploratory Analysis of Selected Population Subgroups in DMIST. Radiology, 246, 376-383. http://dx.doi.org/10.1148/radiol.2461070200

[19] Tabar, L., Chen, H.H.T., Yan, M.F.A., Tot, T., Tung, T.H., Chen, L.S., Chiu, Y.H., Duffy, S.W. and Smith, R.A. (2004) Mammographic Tumor Features Can Predict Long-Term Outcomes Reliably in Women with 1-14-mm Invasive Breast Carcinoma. Cancer, 101, 1745-1759. http://dx.doi.org/10.1002/cncr.20582

[20] Berg, W.A. (2007) Beyond Standard Mammographic Screening: Mammography at Age Extremes, Ultrasound, and MR Imaging. Radiologic Clinics of North America, 45, 895-906. http://dx.doi.org/10.1016/j.rcl.2007.06.001

[21] Berg, W.A., Blume, J.D., Cormack, J.B., Mendelson, E.B., Lehrer, D., Böhm-Vélez, M., Pisano, E.D., Jong, R.A., et al. (2008) Combined Screening with Ultrasound and Mammography vs Mammography Alone in Women at Elevated Risk of Breast Cancer. JAMA, 299, 2151-2163. http://dx.doi.org/10.1001/jama.299.18.2151

[22] Baker, J.A. and Soo, M.S. (2002) Breast Ultrasound: Assessment of Technical Quality and Image Interpretation. Radiology, 23, 229-238.

[23] Stavros, A.T., Thickman, D., Rapp, C.L., Dennis, M.A., Parker, S.H. and Sisney, G.A. (1995) Solid Breast Nodules: Use of Sonography to Distinguish between Benign and Malignant Lesions. Radiology, 196, 123-134.

[24] Benson, S.R., Blue, J., Judd, K. and Harman, J.E. (2004) Ultrasound Is Now Better than Mammography for the Detection of Invasive Breast Cancer. American Journal of Surgery, 188, 381-385. http://dx.doi.org/10.1016/j.amjsurg.2004.06.032

[25] Boonjunwetwat, D., Chyutipraiwan, U., Sampatanukul, P. and Chatamra, K. (2007) Sensitivity of Mammography and Ultrasonography on Detecting Abnormal findIngs of Ductal Carcinoma in Situ. Journal of the Medical Association of Thailand, 90, 539-545.

[26] Malur, S., Wurdinger, S., Moritz, A., Michels, W. and Schneider, A. (2001) Comparison of Written Reports of Mammography, Sonography and Magnetic Resonance Mammography for Preoperative Evaluation of Breast Lesions, with Special Emphasis on Magnetic Resonance Mammography. Breast Cancer Research, 3, 55-60. http://dx.doi.org/10.1186/bcr271

[27] Houssami, N., Irwig, L., Simpson, J.M., McKessar, M., Blome, S. and Noakes, J. (2003) Sydney Breast Imaging Accuracy Study: Comparative Sensitivity and Specificity of Mammography and Sonography in Young Women with Symptoms. American Journal of Roentgenology, 180, 935-940.

[28] Flobbe, K., Nelemans, P.J., Kessels, A.G., Beets, G.L., von Mevenfeldt, M.F. and van Engelshoven, J.M. (2002) The Role of Ultrasonography as an Adjunct to Mammography in the Detection of Breast Cancer: A Systematic Review. European Journal of Cancer, 38, 1044-1050. http://dx.doi.org/10.1016/S0959-8049(01)00388-4

[29] Robinson, M. and Offit, K. (2007) Management of an Inherited Predisposition to Breast Cancer. New England Journal of Medicine, 357, 154-162. http://dx.doi.org/10.1056/NEJMcp071286 
Scientific Research Publishing (SCIRP) is one of the largest Open Access journal publishers. It is currently publishing more than 200 open access, online, peer-reviewed journals covering a wide range of academic disciplines. SCIRP serves the worldwide academic communities and contributes to the progress and application of science with its publication.

Other selected journals from SCIRP are listed as below. Submit your manuscript to us via either submit@scirp.org or Online Submission Portal.
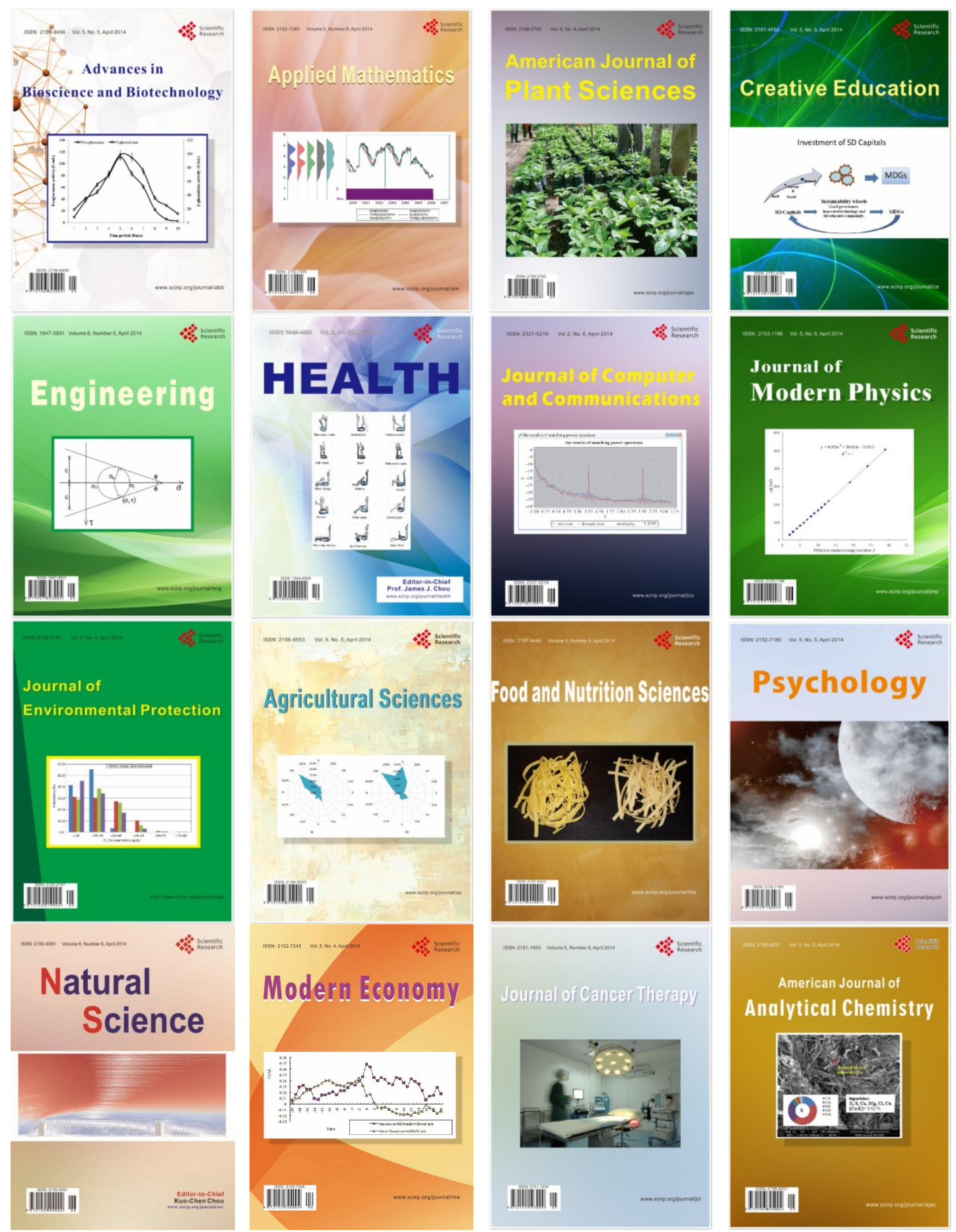